\title{
Affective Response Predicts Risky Choice for Fast, but Not Slow, Decisions
}

Emil Persson, Erkin Asutay, William Hagman, Daniel Västfjäll and Gustav Tinghög

The self-archived postprint version of this journal article is available at Linköping University Institutional Repository (DiVA):

http:/ / urn.kb.se/ resolve?urn=urn:nbn:se:liu:diva-153363

N.B.: When citing this work, cite the original publication.

Persson, E., Asutay, E., Hagman, W., Västfjäll, D., Tinghög, G., (2018), Affective Response Predicts Risky Choice for Fast, but Not Slow, Decisions, J OURNAL OF NEUROSCIENCE PSYCHOLOGY AND ECONOMICS, 11(4), 213-227. https:// doi.org/ 10.1037/ npe0000096

Original publication available at:

https:// doi.org/ 10.1037/ npe0000096

Copyright: American Psychological Association

http:/ / www.apa.org/ 


\title{
Affective Response Predicts Risky Choice for Fast, but Not Slow, Decisions*
}

\author{
Emil Persson ${ }^{\mathrm{a}}$, Erkin Asutay ${ }^{\mathrm{b}}$, William Hagman ${ }^{\mathrm{b}}$, Daniel Västfjäll ${ }^{\mathrm{b}, \mathrm{d}}$, \\ Gustav Tinghög,c \\ a Department of Management and Engineering, Division of Economics, Linköping \\ University, SE-581 83 Linköping, Sweden \\ ${ }^{\mathrm{b}}$ Department of Behavioural Sciences and Learning, Linköping University, SE-581 83 \\ Linköping, Sweden \\ c The National Center for Priority Setting in Health Care, Department of Medical and \\ Health Sciences, \\ Linköping University, SE-581 83 Linköping, Sweden \\ ${ }^{\mathrm{d}}$ Decision Research, 1201 Oak Street, Suite 200, Eugene, Oregon 97401, USA \\ Corresponding author: Emil Persson (emil.persson@liu.se)
}

APA copyright notice: This is a prepublication copy of the final manuscript accepted for publication. This is not the copy of record and may not exactly replicate the authoritative document published in the APA journal. Please do not copy without authors’ permission.

www.apa.org

The final article is available at http://dx.doi.org/10.1037/npe0000096

\footnotetext{
* Financial support from the Marianne and Marcus Wallenberg foundation and the Ragnar Söderberg foundation is gratefully acknowledged. The authors declare no conflict of interest and certify that they have complied with APA ethical standards.
} 


\begin{abstract}
We use skin conductance to measure emotional arousal in subjects who make risky choices under time pressure or time delay. Our results show a strong correlation between subjects’ skin conductance responses and their risky choices under time pressure but not under time delay. Subjects were more risk taking for higher levels of measured electrodermal activity (skin conductance). In line with descriptive theories of risky choice, the effect was most pronounced for choices involving losses rather than gains. Taken together, our findings indicate that participants under time pressure rely on affect at the point of decision-making. This provides support for behavioral models that recognize the role of emotional brain systems in decision making under risk.
\end{abstract}

Keywords: Affect, Measurement, Time pressure, Risk taking, Experiment. 


\section{Introduction}

Economic decisions involving risk and uncertainty are often made in contexts requiring swift action, such as financial trading or auction bidding. Despite its importance, only a small number of studies have investigated the effect of time pressure on risky choice, and the underlying behavioral and emotional mechanisms are complex and to date not fully understood. In this paper, we conduct an experiment to investigate the relationship between risky choice and affect in fast and slow decision-making.

Previous research has shown that affect plays an important role in decision-making under risk (Loewenstein, Hsee, Weber, \& Welch, 2001). One of the most prominent examples is Bechara, Damasio, Tranel, and Damasio (1997), who used a simple gambling task to demonstrate that emotional arousal seemed to precede overt reasoning based on conscious knowledge. Using skin conductance to measure subjects’ emotional arousal when making choices, Bechara et al. found that participants in the experiment registered knowledge of advantageous choices at a nonconscious level well before they learned this on a conscious level and actually made that choice. Importantly, measured electrodermal activity (skin conductance) was stronger as participants made a choice that eventually turned out to be risky. In this sense, affective responses work as emotional cues that are utilized as a heuristic in decision-making. In everyday life, we constantly register and evaluate the affective responses 
that arise in the process of making choice and experiencing its consequences, effectively building a pool of “markers” that guide our future choices based on affect experienced in the past (Bechara \& Damasio, 2005; Finucane, Alhakami, Slovic, \& Johnson, 2000; Slovic, Finucane, Peters, \& MacGregor, 2002).

Affect can thus be viewed as a signal of information that can be relied upon when making decisions, and the physiological manifestation of this signal can be traced using skin conductance. Affect-as-information constitutes an important behavioral component in decisions from experience (such as the Iowa Gambling Task; Bechara et al., 1997), but less is known about its influence in decisions from description (such as standard Prospect Theory gambles; Kahneman \& Tversky, 1979; Tversky \& Kahneman, 1992). In our experiment, we link risky choice to affect using a descriptive choice paradigm based on an extension of Kirchler et al. (2017). We manipulate response times in order to invoke intuitive, affective decision making, and we use skin conductance to measure subjects' autonomic arousal at the point of decision making. ${ }^{1}$

Previous research has shown that skin conductance is correlated with risk taking in behavioral experiments, using different types of choice paradigms (Bechara et al., 1997; Figner, Mackinlay, Wilkening, \&

\footnotetext{
${ }^{1}$ Time pressure is a common manipulation used to invoke intuitive and emotional decision making (Finucane et al., 2000; Rand, Greene, \& Nowak, 2012; Shiv \& Fedorikhin, 1999; Tinghög et al., 2013; Tinghög et al., 2016; Young, Goodie, Hall, \& $\mathrm{Wu}$, 2012). See also Kocher et al. (2018) for a methodological discussion on selection effects in time pressure and risky choice.
} 
Weber, 2009; Sokol-Hessner et al., 2009). It has also been shown that time pressure enhances the role of affect-as-information in decisionmaking (Finucane et al., 2000). This leads to the following two hypotheses for our experiment:

Hypothesis 1: Skin conductance is correlated with risky choice. We expect a stronger skin conductance response when subjects choose a risky option rather than a safe option.

Hypothesis 2: The correlation between skin conductance and risky choice is stronger under time pressure compared to time delay. In the experiment, subjects make binary choices between a safe and a risky option in a series of gambles involving monetary gains or losses. Descriptive behavioral theories as well as empirical findings have come to emphasize the importance of the gain-loss domain distinction in explaining risky choice. It is, arguably, one of the most characteristic features of prospect theory, for example, where it is held that "losses loom larger than gains” (Kahneman \& Tversky, 1979, p. 279). Based on this we can formulate a third hypothesis, concerning the magnitude of skin-conductance responses:

Hypothesis 3: Skin conductance is stronger in the loss domain compared to the gain domain.

We find a strong correlation between subjects' skin conductance (electrodermal activity; EDA) and their risky choices in the time pressure 
treatment but not in the time delay treatment. The effect is driven by decisions taken in the loss domain under time pressure, where a one standard deviation increase in EDA implies that the probability to choose the risky alternative increases with 6.74 percentage points (linear regression, $\mathrm{p}=0.007)$; a substantial effect. Contrary to what we expected, however, we do not find a significant difference in the magnitude of EDA across the gain and loss domain, neither within nor across the two treatments. Taken together, our results show strong support for our main hypothesis (Hypothesis 2), indicating that the time pressure manipulation increases the affect-as-signal content of decision-making in descriptive choices. It is indeed interesting that this effect is so strong despite the fact that there is no discernible difference in the overall magnitude of EDA across the domains. Our findings provide support for behavioral models that recognize the role of emotional brain systems in decision making under risk. Using a time pressure paradigm we also contribute to the neuroscience of dual-process theory, which characterizes human decision making in terms of two distinctive modes of thinking - System 1 and System 2, where System 1 is described as fast, automated and emotional, and System 2 stands for a more controlled and deliberative mode of thinking (Epstein, 1994; Kahneman, 2003, 2011).

Only a few previous studies investigated risky decision making under time pressure using real monetary incentives. Kirchler et al. (2017) found that time pressure increased risk aversion for gains and increased risk 
taking for losses. Kocher, Pahlke, and Trautmann (2013) found no effect on gains but decreased risk taking for losses. Ben Zur and Breznitz (1981) found less risk taking under time pressure for gambles involving both gains and losses, and Nursimulu and Bossaerts (2014) found increased risk aversion for gains under time pressure when preferences were modelled using prospect theory. ${ }^{2}$ We extend this literature by focusing on the affective component of decision making and its different role under time pressure vs no time pressure. Our study is the first to measure subjects' affective response in this context using skin conductance. The response time manipulation had a strong effect on the extent to which subjects' emotional arousal could predict their risky choices. We interpret this as a greater reliance on affective input as a source of information (an affect heuristic) that was primarily recruited when decisions had to be taken very quickly, but not when more time was given (i.e., not in the time delay treatment). This is a novel finding that provides a better understanding of the psychological mechanisms that may drive heuristic processing in fast decisions. Further, these results show that the type of affective processing previously found in decisions from experience (affective learning tasks such as the Iowa Gambling Task) seems to extend to a descriptive choice context.

\footnotetext{
${ }^{2}$ Additionally, El Haji, Krawczyk, Sylwestrzak \& Zawojska (2016) investigated risk taking under time pressure using an auction field experiment, and Madan, Spetch, and Ludvig (2015) investigated the effect of time pressure on decisions from experience.
} 
Our findings also corroborate results from studies in psychology that investigated the affective basis of risky choice more generally (e.g., Charpentier, Neve, Li, Roiser, \& Sharot, 2016; Loewenstein et al., 2001; Mellers \& McGraw, 2001; Mellers, Schwartz, Ho, \& Ritov, 1997; Rutledge, Skandali, Dayan, \& Dolan, 2014). For example, Charpentier et al. (2016) found that feelings associated with losses were more important than feelings associated with gains for predicting choices in mixedgamble trials, despite the fact that the feelings across both domains were similar in terms of magnitude. In this sense, feelings seemed to guide behavior through the relative weight attached to them in the decisionmaking process, rather than through the valence of feelings associated with either gains or losses. Even though we use a different experimental paradigm, the results here speak toward a similar conclusion, since we found that the relationship between emotional arousal and risky choice was more pronounced in the loss domain despite the magnitude of emotional arousal being very similar across the two domains. An advantage of our study is that we use a physiological measurement of affective change, whereas most other studies that investigated affect and risk taking in a prospect theory framework have relied on self-reports (e.g. Mellers et al., 1997). Our experiment thereby extends the previous literature on risky choice and affect, and complements existing studies linking central brain processing to prospect theory (e.g., Fox and Poldrack, 2013). 


\section{Materials and methods}

Experimental design

Subjects made choices in a series of gambles involving risky decisions for pure gain prospects as well as risky decisions for pure loss prospects. Participants were randomly allocated to a time pressure treatment (TP) or a time delay treatment (TD). Whereas subjects in the time pressure treatment had a maximum of seven seconds to make their decision in each gamble, subjects in the time delay treatment had to wait seven seconds before they could submit their decision. The two treatments were identical in all other aspects. Since we were interested in the role of affect at the point of decision making, we chose to compare time pressure with time delay rather than with a baseline without any restrictions in order to maximize the comparable effect of enhancing the role of automated and emotional thinking in subjects vis-à-vis enhancing the role of deliberation and control.

The gambles were divided into two blocks, where one block only involved risk taking in the gain domain and the other block only involved risk taking in the loss domain. The order of the two blocks varied across participants following a pre-specified randomization protocol, and the order of the gambles within each block was randomized at the level of the participant. Each gamble was presented separately to subjects and they made their decision before moving on to the next gamble. In the gain block, subjects made 30 sequential choices between receiving a sum 
of money with certainty and participating in a lottery. The safe option increased from 15 Swedish kronor (SEK) to 80 SEK and the lottery always paid nothing or a fix sum of money with equal probability. ${ }^{3}$ The fix sum of money in the lottery increased from 50 SEK to 150 SEK. In the loss block, the choices were identical except that subjects chose between either losing a sum of money with certainty or participate in a lottery where they would lose either nothing or a fix sum of money with equal probability. The complete list of gambles can be found in the Appendix, Table A1, which also shows how the gambles were binned into five different groups depending on their individual expected value ratios (EVRs).

During the task, participants' electrodermal activity (EDA) was recorded using a BIOPAC MP150 system equipped with a GSR100C amplifier. EDA reflects activity within the sympathetic branch of the autonomic nervous system, and it is usually related to emotional arousal, stress, and orienting to novel stimuli (Boucsein, 1992). Here, it is measured as an indicator of participants' autonomic arousal while they perform the risky choice task. Surface Ag/AgCl electrodes were attached on the medial phalanges of index and middle finger of participants' non-dominant hand.

\footnotetext{
${ }^{3}$ At the time of the experiment, 10 Swedish kronor equaled approximately 1.5 USD.
} 
The experiment was conducted at Linköping University in Sweden. Subjects were students recruited through e-mail advertisement and the experiment was conducted using a computerized survey interface. Only one subject participated in each session, which meant that subjects were randomized into treatment at the level of the individual. Subjects received written instructions (see online Supplementary material) and were given plenty of time to read and ask questions before the experiment begun. All decisions were made in private. Subjects received a 150 SEK show-up fee in cash at the beginning of the experiment and they knew that one decision would be randomly selected for additional payment at the end of the experiment. If the subject had chosen the lottery (rather than the safe option) in the particular decision that was randomly selected, the experimenter would flip a coin to determine the outcome of the lottery. If a decision from the loss block was selected, the realized loss would be deducted from the subject's show-up fee. If the subject had not responded on time in the time pressure treatment and a decision from the gain block was selected for payment, he or she received no payment from that decision. If instead a decision from the loss block was selected for payment, the subject who had failed to respond in time in the time pressure treatment received no show-up fee for the experiment. Subjects were informed about these rules and they were clearly stated in the instructions. In total, 40 subjects participated in the experiment and they were equally divided across the two treatments. 
There were 12 men and 8 women in each treatment, mean (SD) age was 23.60 (2.87) years in TD and 21.89 (1.94) years in TP. Subjects earned on average 172.75 SEK ( 21 USD at the time of the experiment) and a session lasted approximately 50 minutes.

\section{Data analysis}

The gambles used in the experiment were binned into five different groups depending on their individual expected value ratios (EVRs), calculated as the value of the safe option (A) relative to the expected value of the gamble (B), i.e., $\mathrm{EVR}=\mathrm{EV}_{\mathrm{A}} / \mathrm{EV}_{\mathrm{B}}$ (see Table A1 for more details). We compared the proportion of coin-toss choices (the gambling rate) across the two treatments, using t-tests with standard errors clustered on the level of the individual. The gambling rate was also calculated within each EVR for each participant and treatment. Generally, the proportion of risky choices should decrease with increasing EVR. We expected this behavior in the gain domain. However, since we coded EVRs with a minus sign in the loss domain, the gambling rate should increase with EVR (see Figure 1).

Next, individual psychometric functions were fitted to the behavioral data in order to examine the changes in participants' choices as a function of EVRs. We fitted a sigmoid function, which is a widely used psychometric function in psychophysics (Wichmann \& Hill, 2001), to the behavioral data. The function was defined as:

$y(x)=[\operatorname{Ymax}+\operatorname{Ymin} * \exp ((x-X c) / b)] /[1+\exp ((x-X c) / b)]$, 
where $y$ is the dependent variable (the gambling rate) and $x$ is the independent variable (EVRs). The upper and lower saturation limits of the function were represented as Ymax and Ymin. Since the dependent variable is a percentage the function upper and lower limits have to be between 0 and 1. We set Ymin and Ymax to 0.01 and 0.99 , respectively (setting the upper and lower limits to 1 and 0 yielded the same results). $\mathrm{X} c$ represents the value of the independent variable at the central point of the sigmoid (i.e., the EVR value where $\mathrm{y}$ is $50 \%$ ), and $b$ is the slope of the function around the central point. The central point $\left(X_{C}\right)$ and the slope around the central point $(b)$ were estimated using non-linear least squares. Root mean square error (RMSE) was taken as a measure of the goodness-of-fit. One sigmoid function was fitted for each individual and for each domain (gain and loss). $X c$ represents the EVR where participants were indifferent between the safe and risky option, and $b$ is an estimate of the sharpness of the transition between choosing the risky option and the safe option as a function of the change in EVR. Three participants in each treatment were excluded since their data did not provide a good fit; the RMSE was higher for the estimated sigmoid function than when the mean was fitted to the data set. The main reason was that these participants tended to choose either the safe or the risky option throughout the entire experiment, or they did not respond to the changing expected value ratios of the individual gambles. 
For both treatment groups, the physiological data, EDA, was scored for each trial within a seven-second time window that started one second after the bet appeared on the screen. Further, for the time-delay treatment we also scored EDA in an additional seven-second time window that started one second after the beginning of the response period. These time windows depended on the particular trial-timings in respective groups. Hence, for the time-delay treatment, EDA was scored in two separate time windows, first when the participants viewed the gamble (TD-view) and then again when they made a choice (TD-response). Within a particular time-window, the signals were band-pass filtered between 0.2 and $3 \mathrm{~Hz}$. The lower-frequency limit was introduced in order to remove the slow-adapting tonic component of EDA, while the higher limit was applied to filter out the high frequency noise. The resulting signal was full-wave rectified and integrated to a single value. Finally, the data was log-transformed before it was standardized for each participant (Figner \& Murphy, 2011). Standardization of EDA is a general practice in order to remove the inter-individual variation in physiological responding. In the analysis, we compare EDA across treatments and domains (gain and loss) using independent-sample t-tests. For ease of comparison, we focus on TD-response rather than TD-view in the time delay treatment (which does not affect our main results, see Appendix).

Ethics statement 
We consulted the ethical review board for East Sweden to determine whether a formal approval of the committee was required. It was concluded that a formal assessment by the Ethics Committee was not necessary because the participants were given full disclosure of the procedure (i.e., there was no deceit), participants received a payment proportionate to the task, the experimental procedure was noninvasive and the results were analyzed anonymously. Furthermore, the participants voluntarily subscribed for participation and they were informed that participation was voluntary and anonymous. They were also informed that they could withdraw from the experiment at any time.

\section{Results}

\section{Behavioral data}

We begin by looking at the behavioral responses. Figure 1 plots the mean choice for each gamble by treatment and domain. Time pressure led to a decrease in risk taking in the loss domain for most gambles and to a small increase in risk taking in the gain domain, but the differences are not significant when we account for subjects’ repeated decision making in the experiment (Table 1). We further investigated how risk taking varied across the different EVR bins. As EVR increased, participants increasingly inclined towards the safe option in the gain domain, while in the loss domain the results were as could be expected in the opposite direction. For example, in the gain domain, the risky option was chosen 
$88.96 \%$ of the time in EVR 1 but only $22.50 \%$ of the time in EVR 5 (ttest, $\mathrm{p}<0.001$ ); and in the loss domain, the risky option was chosen 15.09 \% of the time in EVR 1 and $73.58 \%$ of the time in EVR 5 (t-test, $\mathrm{p}<0.001)$

Figure 1 about here

\section{Table 1 about here}

Two psychometric functions were fitted to the behavioral data for each individual: one for the loss domain and one for the gain domain (see Materials and methods section for details). Individually estimated parameters (absolute value of the central point of the function and the slope around the central point) were compared between the different domains and treatment groups using independent-sample t-tests. Figure 2 illustrates the group average of the estimated functions for each of the two treatment groups. We can see that the central point tends to occur at a higher EVR (t-test, $\mathrm{p}=0.07)$ for the time-pressure treatment $(1.074 \pm$ 0.036) compared to the time-delay treatment $(0.990 \pm 0.028)$ in the loss domain, but there was no significant difference between the treatments in the gain domain. Comparison of the slopes did not yield any significant difference. Taken together, these results indicate that time pressure decrease risk taking for losses, and we can see in Figure 2 that this effect becomes stronger as the EVR of the gamble increases.

Figure 2 about here 


\section{Physiological data}

Turning to the physiological responses, we first examined the correlation between participants' electrodermal activity (EDA) and their risky choices, using t-tests with standard errors clustered on the level of the individual. The correlation between EDA and individual choice is not significant in the pooled sample, comprising both the time pressure and time delay treatment (t-test, $\mathrm{p}=0.187)$. This result does not give support for Hypothesis 1. However, when we investigate the relationship between EDA and risky choice separately for each treatment, we find a significant correlation under time pressure (t-test, $\mathrm{p}=0.023$ ) but not under time delay (t-test, $\mathrm{p}=0.429)$. The difference between treatments is statistically significant ( $\mathrm{t}$-test, $\mathrm{p}=0.018$ ). Moreover, as can be seen in Table 2 , the effect in the time-pressure treatment is driven by decisions taken in the loss domain.

\section{Table 2 about here}

Figure 3 illustrates the strong relationship between emotional arousal and behavior found in the time-pressure treatment. The figure plots the predicted probability to choose the risky option, i.e., to gamble, against the level of EDA. In the loss domain, we can see the relationship very clearly: the probability to gamble ranges from only 0.15 for very low levels of arousal (EDA=-3) to over 0.5 at high levels of arousal. Taken together, the marginal effect of EDA on the probability to gamble is 6.97 percentage points $(\mathrm{p}=0.007)$. The effect is still strong (5.24 percentage 
points, $\mathrm{p}=0.022$ ) when decisions in the gain and loss domains are analyzed jointly, but the corresponding effect in the time-delay treatment is small and insignificant ( -1.36 percentage points, $\mathrm{p}=0.428)$. There is thus a substantial effect of time pressure and this is in line with Hypothesis 2, which is our main hypothesis. Thus, when decision time is short, participants seem to rely on affect at the point of decision-making, especially for gambles involving losses.

\section{Figure 3 about here}

We then investigated whether EDA was stronger in the loss domain compared to the gain domain, and again we used t-tests with standard errors clustered on the level of the individual. Surprisingly, the differences we found were small and generally insignificant. On average, there is neither a difference across domains in the pooled sample (t-test, $\mathrm{p}=0.272$ ) nor in any of the two treatments investigated separately (t-test, time pressure $\mathrm{p}=0.303$, time delay $\mathrm{p}=0.662$ ). This can also be confirmed by looking at Figure 4, which plots the mean EDA difference between gains and losses. However, we can see in the figure that the EDA difference fluctuates somewhat stronger in the time pressure treatment, and the effect is stronger for gambles with a comparatively low EVR. Taken together, people in the experiment seem to differentiate stronger between gains and losses under time pressure, but we do not find support for Hypothesis 3 regarding domain asymmetries in the magnitude of EDA. 
Figure 4 about here

\section{Discussion and conclusion}

We investigate the relationship between risky choice and affect in fast

(i.e. time pressured) and slow (i.e. time delayed) decisions. Our main

finding is the strong correlation between subjects' electrodermal activity

and their risky choices that was found in the time pressure treatment but

not in the time delay treatment. Whereas the effect is driven by decisions

taken in the loss domain, the overall level of arousal does not differ

between the gain and loss domain.

A strength of our study is that subjects chose repeatedly for a range of

different stake sizes and expected value ratios of the individual gambles,

yielding variation at the level of the individual that is important when

using skin conductance. This enables us to test whether electrodermal

activity (EDA) is different across safe and risky choices in any of the two

treatments. Using simulations ${ }^{4}$ and setting alpha $=0.05$ we calculated that

\footnotetext{
${ }^{4}$ We attempted to estimate the statistical power to find a weak effect that EDA is higher for the trials where participants selected the risky option compared to the trials where participants selected the safe option using simulations, which were carried out after the data collection. Since we found a significant difference in EDA only within the time pressure treatment in the loss domain, we carried out simulations for a sample size of 20 individuals with 30 data points each (15 safe and 15 risky options). We simulated data points for each individual randomly selected from a population distribution, in which the average EDA was set to 0 and the standard deviation was set to 1 . Since the actual measured data is z-scored, the mean and the standard deviation is 0 and 1 , respectively. The mean difference between the safe and the risky options was set to 0.2 , which would mean an effect size of 0.2 standard deviations. We generated 10,000 different samples $(\mathrm{N}=20$ in each of them) and used t-test with standard errors clustered at the individual level to analyze EDA difference (risky vs. safe option) for each generated sample (i.e. the same analysis we used to analyze the measured data). The proportion of simulations showing a significant effect in the expected direction was 0.69 . Further, when we
} 
the statistical power to detect an EDA difference of at least 0.2 standard deviations was around 0.7 for each treatment and domain. The power of the study is thus arguably sufficient given our research objectives. Our experiment was, however, not designed to test the effect of time pressure and time delay on choice behavior alone, and we therefore refrain from drawing any strong conclusions about the behavioral effects observed in the experiment since this is not the focus of our paper. A cautious interpretation of the behavioral data suggests that there are no strong behavioral effects of time pressure, except that risk taking in the loss domain seemed to decrease under time pressure for gambles that had a relatively high expected value ratio. Based on prospect theory, one would probably have expected the opposite effect, i.e., more risk averse for gains and more risk taking for losses when decision time is short (Kirchler et al., 2017). This is also the most common results among studies that used other types of manipulations to invoke emotional and intuitive decision-making, such as acute stress or cognitive load (e.g., Cahlíková \& Cingl, 2017; Deck \& Jahedi, 2015; Porcelli \& Delgado, 2009). However, our behavioral results can still be reconciled with traditional prospect theory if one is willing to make further assumptions. For example, Saqib and Chan (2015) also found that risk taking decreased in the loss domain under time pressure (in hypothetical 
gambles). They argue that time pressure shifts the reference point, because people rely on decision-making heuristics and therefore focus on the maximal outcome of the gamble rather than the status quo, which in turn makes them more risk taking in the gain domain but less risk taking in the loss domain.

Relying on emotions at the point of decision making can be advantageous, as demonstrated by Bechara et al. (1997) and subsequent studies, but it may also introduce a bias (Vohs, Baumeister, \& Loewenstein, 2007). In general, affect is believed to influence decision making and judgement in two different ways, either through affect that is integral to the decision under consideration, or through affect that is incidental, i.e. unrelated to the target of the decision (Neumann, Seibt, \& Strack, 2001; Schwarz \& Clore, 1983; Västfjäll et al., 2016). Mood is an example of incidental affect. On part of the decision maker, incidental affect such as mood is not a relevant source of information, at least not in most contexts; it rather introduces a bias when misattributed to the target of the decision. Previous research has shown that time pressure can increase use of incidental affective information (e.g. mood) in judgments (Siemer \& Reisenzein, 1998) and that integral, salient, affective cues (e.g. image of a chocolate cake) can receive greater weight under reduced processing capabilities (Shiv \& Fedorikhin, 2002). Our results extend this by showing that reliance on integral affective responses may increase under time pressure - even when the choice task is relatively affect-poor 
(i.e. gambles; Rottenstreich \& Hsee, 2001). In our case, the heuristic use of affective information associated with risky prospects (i.e. integral affect) increase under restrained processing capabilities, which suggest that time pressure may not always lead to bad decisions. Framed differently, deciding fast may be just as good as deciding slow - at least when relevant affective input can be derived from the choice alternatives.

\section{References}

Bechara, A., \& Damasio, A. R. (2005). The somatic marker hypothesis: A neural theory of economic decision. Games and Economic Behavior, 52(2), 336-372. doi:10.1016/j.geb.2004.06.010

Bechara, A., Damasio, H., Tranel, D., \& Damasio, A. R. (1997). Deciding advantageously before knowing the advantageous strategy. Science, 275(5304), 1293. doi:10.1126/science.275.5304.1293

Ben Zur, H., \& Breznitz, S. J. (1981). The effect of time pressure on risky choice behavior. Acta Psychologica, 47(2), 89-104. doi:10.1016/0001-6918(81)90001-9

Boucsein, W. (1992). Electrodermal Activity. New York: Plenum Press.

Cahlíková, J., \& Cingl, L. (2017). Risk preferences under acute stress. Experimental Economics, 20(1), 209-236. doi:10.1007/s10683016-9482-3

Charpentier, C. J., Neve, J.-E. D., Li, X., Roiser, J. P., \& Sharot, T. (2016). Models of affective decision making. Psychological Science, 27(6), 763-775. doi:doi:10.1177/0956797616634654

Deck, C., \& Jahedi, S. (2015). The effect of cognitive load on economic decision making: A survey and new experiments. European Economic Review, 78, 97-119. doi:10.1016/j.euroecorev.2015.05.004

Epstein, S. (1994). Integration of the cognitive and the psychodynamic unconscious. American Psychologist, 49(8), 709-724. doi:10.1037/0003-066X.49.8.709 
Figner, B., Mackinlay, R. J., Wilkening, F., \& Weber, E. (2009). Affective and deliberative processes in risky choice: age differences in risk taking in the Columbia Card Task. Journal of Experimental Psychology: Learning, Memory, and Cognition, 35(3), 709-730. doi:10.1037/a0014983

Figner, B., \& Murphy, R. O. (2011). Using skin conductance in judgment and decision making research. In M. Schulte-Mecklenbeck, A. Kühberger, R. Ranyard, M. Schulte-Mecklenbeck, A. Kühberger, \& R. Ranyard (Eds.), A Handbook of Process Tracing Methods for Decision Research: A Critical Review and User's Guide. (pp. 163-184). New York, NY, US: Psychology Press.

Finucane, M., Alhakami, A., Slovic, P., \& Johnson, S. M. (2000). The affect heuristic in judgments of risks and benefits. Journal of Behavioral Decision Making, 13(1), 1-17. doi:10.1002/(SICI)1099-0771(200001/03)13:1<1::AIDBDM333>3.0.CO;2-S

Fox, C. R., \& Poldrack, R. A. (2014). Prospect theory and the brain. In P. W. Glimcher \& E. Fehr (Eds.), Neuroeconomics: Decision Making and the Brain (Second edition ed., pp. 553-563). Amsterdam: Academic Press.

Kahneman, D. (2003). A perspective on judgment and choice: mapping bounded rationality. American Psychologist, 58(9), 697-720. doi:10.1037/0003-066X.58.9.697

Kahneman, D. (2011). Thinking, Fast and Slow. New York: Farrar, Straus and Giroux.

Kahneman, D., \& Tversky, A. (1979). Prospect theory: An analysis of decision under risk. Econometrica, 47(2), 263-291. doi:10.2307/1914185

Kirchler, M., Andersson, D., Bonn, C., Johannesson, M., Sørensen, E., Stefan, M., .. . Västfjäll, D. (2017). The effect of fast and slow decisions on financial risk taking. Journal of Risk and Uncertainty, 54, 37-59. doi:10.1007/s11166-017-9252-4

Kocher, M. G., Pahlke, J., \& Trautmann, S. T. (2013). Tempus fugit: Time pressure in risky decisions. Management Science, 59(10), 2380-2391. doi:10.1287/mnsc.2013.1711

Kocher, M. G., Schindler, D., Trautmann, S. T., \& Xu, Y. (2018). Risk, time pressure, and selection effects. Experimental Economics. doi:10.1007/s10683-018-9576-1 
Loewenstein, G., Hsee, C., Weber, E., \& Welch, N. (2001). Risk as feelings. Psychological Bulletin, 127(2), 267-286.

doi:10.1037/0033-2909.127.2.267

Madan, C. R., Spetch, M. L., \& Ludvig, E. A. (2015). Rapid makes risky: Time pressure increases risk seeking in decisions from experience. Journal of Cognitive Psychology, 27(8), 921-928. doi:10.1080/20445911.2015.1055274

Mellers, B. A., \& McGraw, A. P. (2001). Anticipated emotions as guides to choice. Current Directions in Psychological Science, 10(6), 210-214. doi:doi:10.1111/1467-8721.00151

Mellers, B. A., Schwartz, A., Ho, K., \& Ritov, I. (1997). Decision affect theory: Emotional reactions to the outcomes of risky options. Psychological Science, 8(6), 423-429. doi:10.1111/j.14679280.1997.tb00455.x

Neumann, R., Seibt, B., \& Strack, F. (2001). The influence of mood on the intensity of emotional responses: Disentangling feeling and knowing. Cognition and Emotion, 15(6), 725-747. doi:10.1080/02699930143000266

Nursimulu, A. D., \& Bossaerts, P. (2014). Risk and Reward Preferences under Time Pressure. Review of Finance, 18(3), 999-1022. doi:10.1093/rof/rft013

Porcelli, A. J., \& Delgado, M. R. (2009). Acute stress modulates risk taking in financial decision making. Psychological Science, 20(3), 278-283. doi:doi:10.1111/j.1467-9280.2009.02288.x

Rand, D. G., Greene, J. D., \& Nowak, M. A. (2012). Spontaneous giving and calculated greed. Nature, 489(7416), 427-430. doi:10.1038/nature11467

Rottenstreich, Y., \& Hsee, C. K. (2001). Money, Kisses, and Electric Shocks: On the Affective Psychology of Risk. Psychological Science, 12(3), 185-190. doi:10.1111/1467-9280.00334

Rutledge, R. B., Skandali, N., Dayan, P., \& Dolan, R. J. (2014). A computational and neural model of momentary subjective wellbeing. Proceedings of the National Academy of Sciences, 111(33), 12252-12257. doi:10.1073/pnas.1407535111

Saqib, N. U., \& Chan, E. Y. (2015). Time pressure reverses risk preferences. Organizational Behavior and Human Decision Processes, 130, 58-68. doi:10.1016/j.obhdp.2015.06.004 
Schwarz, N., \& Clore, G. L. (1983). Mood, misattribution and judgments of well-being: informative and directive functions of affective states. Journal of Personality and Social Psychology, 45(3), 513523. doi:10.1037/0022-3514.45.3.513

Shiv, B., \& Fedorikhin, A. (1999). Heart and Mind in Conflict: the Interplay of Affect and Cognition in Consumer Decision Making. Journal of Consumer Research, 26(3), 278-292. doi:10.1086/209563

Shiv, B., \& Fedorikhin, A. (2002). Spontaneous versus Controlled Influences of Stimulus-Based Affect on Choice Behavior. Organizational Behavior and Human Decision Processes, 87(2), 342-370. doi:10.1006/obhd.2001.2977

Siemer, M., \& Reisenzein, R. (1998). Effects of mood on evaluative judgements: Influence of reduced processing capacity and mood salience. Cognition and Emotion, 12(6), 783-805.

doi:10.1080/026999398379439

Slovic, P., Finucane, M., Peters, E., \& MacGregor, D. G. (2002). The affect heuristic. In D. Griffin, D. Kahneman, \& T. Gilovich (Eds.), Heuristics and Biases: The Psychology of Intuitive Judgment (pp. 397-420). Cambridge: Cambridge University Press.

Sokol-Hessner, P., Hsu, M., Curley, N. G., Delgado, M. R., Camerer, C. F., \& Phelps, E. A. (2009). Thinking like a trader selectively reduces individuals' loss aversion. Proceedings of the National Academy of Sciences, 106(13), 5035-5040. doi:10.1073/pnas.0806761106

Tinghög, G., Andersson, D., Bonn, C., Bottiger, H., Josephson, C., Lundgren, G., . . . Johannesson, M. (2013). Intuition and cooperation reconsidered. Nature, 498(7452), E1-E2. doi:10.1038/nature12194

Tinghög, G., Andersson, D., Bonn, C., Johannesson, M., Kirchler, M., Koppel, L., \& Västfjäll, D. (2016). Intuition and Moral DecisionMaking - The Effect of Time Pressure and Cognitive Load on Moral Judgment and Altruistic Behavior. PloS One, 11(10), e0164012. doi:10.1371/journal.pone.0164012

Tversky, A., \& Kahneman, D. (1992). Advances in prospect theory: Cumulative representation of uncertainty. Journal of Risk and Uncertainty, 5(4), 297-323. doi:10.1007/bf00122574 
Wichmann, F. A., \& Hill, N. J. (2001). The psychometric function: I.

Fitting, sampling, and goodness of fit. Perception and

Psychophysics, 63(8), 1293-1313. doi:10.3758/bf03194544

Vohs, K. D., Baumeister, R. F., \& Loewenstein, G. (2007). Do Emotions Help or Hurt Decisionmaking? A Hedgefoxian Perspective. New York: Russell Sage Foundation.

Västfjäll, D., Slovic, P., Burns, W., Erlandsson, A., Koppel, L., Asutay, E., \& Tinghög, G. (2016). The arithmetic of emotion: Integration of incidental and integral affect in judgments and decisions. Frontiers in Psychology, 7, 325. doi:10.3389/fpsyg.2016.00325

Young, D. L., Goodie, A. S., Hall, D. B., \& Wu, E. (2012). Decision making under time pressure, modeled in a prospect theory framework. Organizational Behavior and Human Decision Processes, 118(2), 179-188. doi:10.1016/j.obhdp.2012.03.005 


\section{Appendix}

Parameters used for all choices in the experiment

Table A1 about here

Main results using TD-view instead of TD-response

The main results of the paper are similar when we use electrodermal activity (EDA) that was scored when participants viewed the gamble (TD-view) instead of EDA scored when they made their choice (TDresponse). Under time pressure we find a significantly stronger EDA when the risky option was chosen instead of the safe option (t-test, $\mathrm{p}=0.023)$, but there is no similar effect in the time-delay treatment (t-test, $\mathrm{p}=0.538$ ). Table A2 shows average EDA by treatment and gambling choice separately for each domain. Figure A1 plots the predicted probability to choose the risky option against the level of EDA and Figure A2 plots the mean EDA difference between gains and losses. Table A2 about here

Figures A1-A2 about here

Main results using nonparametric tests instead of t-tests with clustered standard errors

Our main finding is the strong correlation between subjects’ electrodermal activity (EDA) and their risky choices that was found in the time pressure treatment but not in the time delay treatment. This was 
for example visible in Table 2 where EDA was significantly higher in the loss domain under time pressure when subjects chose the risky option instead of the safe option. Here we show that this result is robust to using a more conservative analysis that does not rely on regression analysis with clustered standard errors. For every subject we first calculated average EDA for each domain and gambling choice. Then we used a Wilcoxon signed-rank test to investigate whether average EDA depended on the choices subjects made, thus using only $\mathrm{N}=20$ for each test (Table A3). We found a significant difference only in the loss domain under time pressure and this is consistent with the main results presented in the paper.

Table A3 about here 
Tables

Table 1. Descriptive behavioral results

\begin{tabular}{|l|c|c|c|c|}
\hline & \multicolumn{2}{|c|}{ Treatment } & \multicolumn{2}{c|}{ P-value of TD vs TP } \\
\hline & TD & TP & t-test ${ }^{\text {a }}$ & $\begin{array}{c}\text { Mann- } \\
\text { Whitney }\end{array}$ \\
\hline GAIN: Gambling rate: \% (SD) & $\begin{array}{c}61.99 \\
(48.58)\end{array}$ & $\begin{array}{c}65.42 \\
(47.60)\end{array}$ & $\begin{array}{c}0.610 \\
{[\mathrm{n}=1179]}\end{array}$ & $\begin{array}{c}0.473 \\
{[\mathrm{n}=40]}\end{array}$ \\
\hline LOSS: Gambling rate: \% (SD) & $\begin{array}{c}42.88 \\
(49.53)\end{array}$ & $\begin{array}{c}33.73 \\
(47.32)\end{array}$ & $\begin{array}{c}0.129 \\
{[\mathrm{n}=1174]}\end{array}$ & $\begin{array}{c}0.126 \\
{[\mathrm{n}=40]}\end{array}$ \\
\hline GAIN: Missing responses: \% & 1.33 & 2.17 & & \\
\hline LOSS: Missing responses: \% & 1.67 & 2.67 & & \\
\hline N & 20 & 20 & & \\
\hline
\end{tabular}

Note: ${ }^{\text {a }}$ Standard errors are clustered at the level of the individual. Each individual made 30 choices in the gain domain and 30 choices in the loss domain, which amounts to 1200 choices in each domain in total. ${ }^{\mathrm{b}}$ For the Mann-Whitney U test we use the average choice of each individual as the unit of observation. 
Table 2. Average EDA [z-score] by domain, treatment and gambling choice

\begin{tabular}{|l|c|c|c|c|}
\hline & \multicolumn{2}{|c|}{ TP } & \multicolumn{2}{c|}{ TD } \\
\hline & Gain & Loss & Gain & Loss \\
\hline Safe option chosen & 0.032 & -0.194 & 0.114 & -0.032 \\
\hline Risky option chosen & 0.085 & 0.096 & -0.029 & -0.025 \\
\hline Difference & -0.053 & -0.290 & 0.143 & -0.007 \\
\hline P-value (t-test ${ }^{a}$ ) & 0.674 & 0.007 & 0.104 & 0.950 \\
\hline
\end{tabular}

Note: ${ }^{\text {a }}$ Standard errors are clustered at the level of the individual. 
Table A1. Overview of the risk decisions divided into five bins of expected value ratios (EVRs)

\begin{tabular}{|c|c|c|c|}
\hline & $\begin{array}{l}\text { Option A: Safe Amount } \\
\text { (SWE SEK) }\end{array}$ & $\begin{array}{l}\text { Option B: Amounts in 50-50 Gamble } \\
\text { (SWE SEK) }\end{array}$ & $\begin{array}{c}\mathbf{E V R} \\
\left(\mathrm{EV}_{\mathrm{A}}\right. \\
\left.\mathrm{EV}_{\mathrm{B}}\right)\end{array}$ \\
\hline \multirow[t]{8}{*}{ EVR 1} & 15 & $0 / 50$ & 0.60 \\
\hline & 20 & $0 / 60$ & 0.67 \\
\hline & 35 & $0 / 100$ & 0.70 \\
\hline & 45 & $0 / 120$ & 0.75 \\
\hline & 30 & $0 / 80$ & 0.75 \\
\hline & 40 & $0 / 100$ & 0.80 \\
\hline & 60 & $0 / 150$ & 0.80 \\
\hline & 20 & $0 / 50$ & 0.80 \\
\hline \multirow[t]{7}{*}{ EVR 2} & 25 & $0 / 60$ & 0.83 \\
\hline & 50 & $0 / 120$ & 0.83 \\
\hline & 65 & $0 / 150$ & 0.87 \\
\hline & 35 & $0 / 80$ & 0.88 \\
\hline & 45 & $0 / 100$ & 0.90 \\
\hline & 55 & $0 / 120$ & 0.92 \\
\hline & 70 & $0 / 150$ & 0.93 \\
\hline \multirow[t]{6}{*}{ EVR 3} & 25 & $0 / 50$ & 1.00 \\
\hline & 30 & $0 / 60$ & 1.00 \\
\hline & 40 & $0 / 80$ & 1.00 \\
\hline & 50 & $0 / 100$ & 1.00 \\
\hline & 60 & $0 / 120$ & 1.00 \\
\hline & 75 & $0 / 150$ & 1.00 \\
\hline \multirow[t]{5}{*}{ EVR 4} & 80 & $0 / 150$ & 1.07 \\
\hline & 65 & $0 / 120$ & 1.08 \\
\hline & 55 & $0 / 100$ & 1.10 \\
\hline & 45 & $0 / 80$ & 1.13 \\
\hline & 35 & $0 / 60$ & 1.17 \\
\hline \multirow[t]{2}{*}{ EVR 5} & 30 & $0 / 50$ & 1.20 \\
\hline & 50 & $0 / 80$ & 1.25 \\
\hline
\end{tabular}




\begin{tabular}{|c|c|c|}
\hline 40 & $0 / 60$ & 1.33 \\
\hline 35 & $0 / 50$ & 1.40 \\
\hline
\end{tabular}

Note: Expected value ratios (EVRs) were calculated as the value of the safe option (A) relative to the expected value of the gamble (B), i.e. $E V R=\mathrm{EV}_{\mathrm{A}} / \mathrm{EV}_{\mathrm{B}}$. Then, the gambles were binned into five different groups depending on their individual EVRs. 
Table A2. Average EDA [z-score] by domain, treatment and gambling choice

\begin{tabular}{|l|c|c|c|c|}
\hline & \multicolumn{2}{|c|}{ TP } & \multicolumn{2}{c|}{ TD-view } \\
\hline & Gain & Loss & Gain & Loss \\
\hline Safe option chosen & 0.032 & -0.194 & 0.019 & -0.053 \\
\hline Risky option chosen & 0.085 & 0.096 & -0.027 & 0.046 \\
\hline Difference & -0.053 & -0.290 & 0.045 & -0.099 \\
\hline P-value (t-test ${ }^{a}$ ) & 0.674 & 0.007 & 0.572 & 0.314 \\
\hline
\end{tabular}

Note: ${ }^{\text {a }}$ Standard errors are clustered at the level of the individual. 
Table A3. Average EDA [z-score] by domain, treatment and gambling choice

\begin{tabular}{|l|c|c|c|c|}
\hline & \multicolumn{2}{|c|}{ TP } & \multicolumn{2}{c|}{ TD } \\
\hline & Gain & Loss & Gain & Loss \\
\hline Safe option chosen & 0.083 & -0.167 & 0.126 & -0.067 \\
\hline Risky option chosen & 0.066 & 0.113 & 0.020 & -0.045 \\
\hline Difference & 0.017 & -0.280 & 0.106 & -0.022 \\
\hline P-value (paired t-test) & 0.880 & 0.016 & 0.422 & 0.834 \\
\hline P-value (Wilcoxon signed-rank test) & 0.881 & 0.019 & 0.435 & 0.941 \\
\hline N & 20 & 20 & 17 & 20 \\
\hline
\end{tabular}

Note: For every subject we first calculated average EDA for each domain and gambling choice. Then within each domain and treatment we tested the difference in EDA for safe option chosen vs. risky option chosen. Data for three individuals in the time delay treatment was excluded from analysis in the gain domain since there was no variation in their choices. 


\section{Figures}

Figure 1. Proportion of subjects who chose the risky option, by treatment and domain
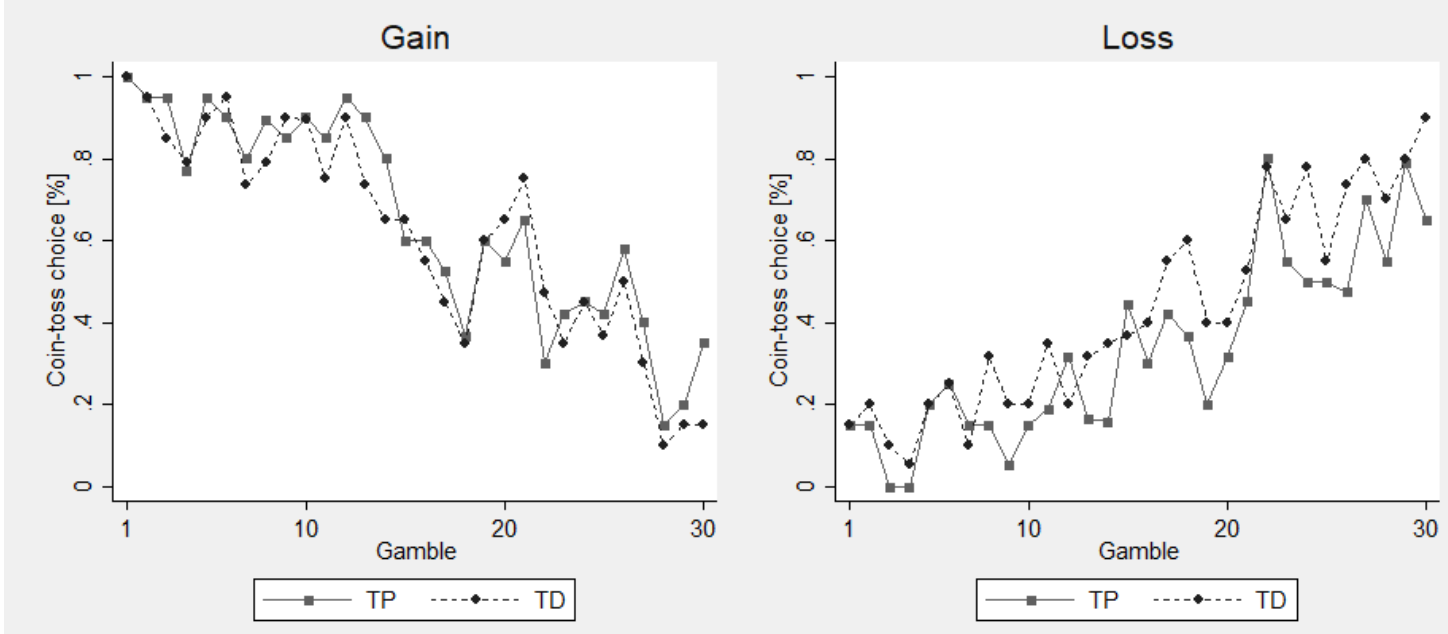

Note: The gambles are ranked by EVR, from lowest to highest. 
Figure 2. Individual psychometric functions relating risky choice to the expected value ratio of the gambles, by treatment and domain
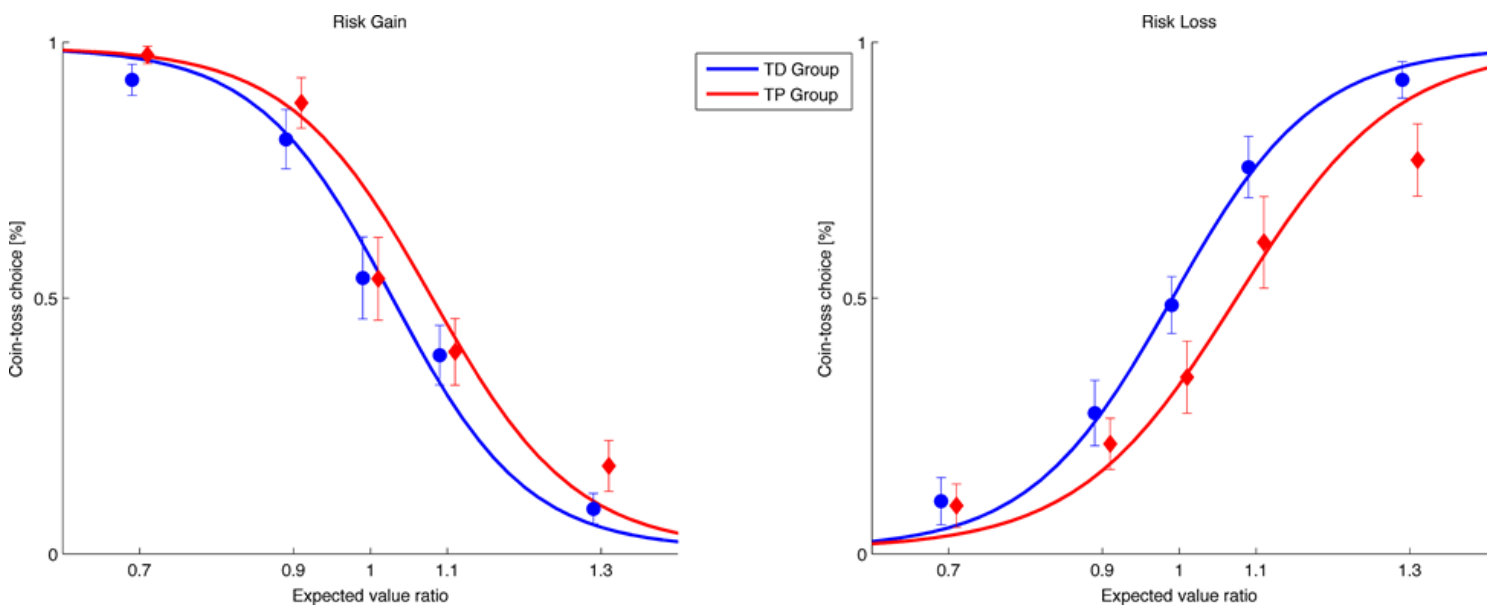

Note: See Materials and methods for a detailed description of the sigmoid functions.

The dots show the gambling rate (risky option chosen) within EVR bins 1-5, and confidence intervals are based on independent-sample t-tests. Expected value ratios (EVRs) were calculated as the value of the safe option (A) relative to the expected value of the gamble (B). 
Figure 3. Predicted probability to gamble, by EDA, treatment and domain
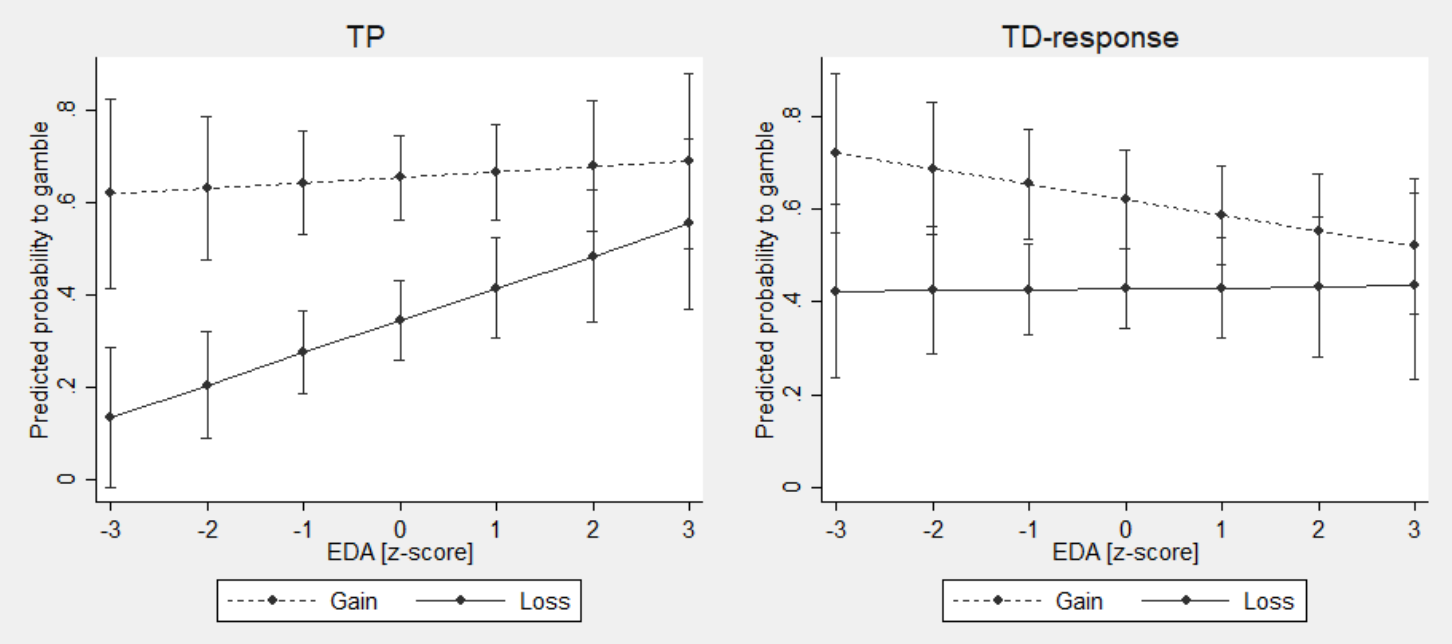

Note: Linear prediction calculated from OLS regressions of subjects' binary choice (=1 if chose to gamble) on EDA, standard errors clustered at the level of the individual. Bars represent $95 \%$ confidence intervals. 
Figure 4. Gain-loss difference (average EDA) across all gambles in the experiment
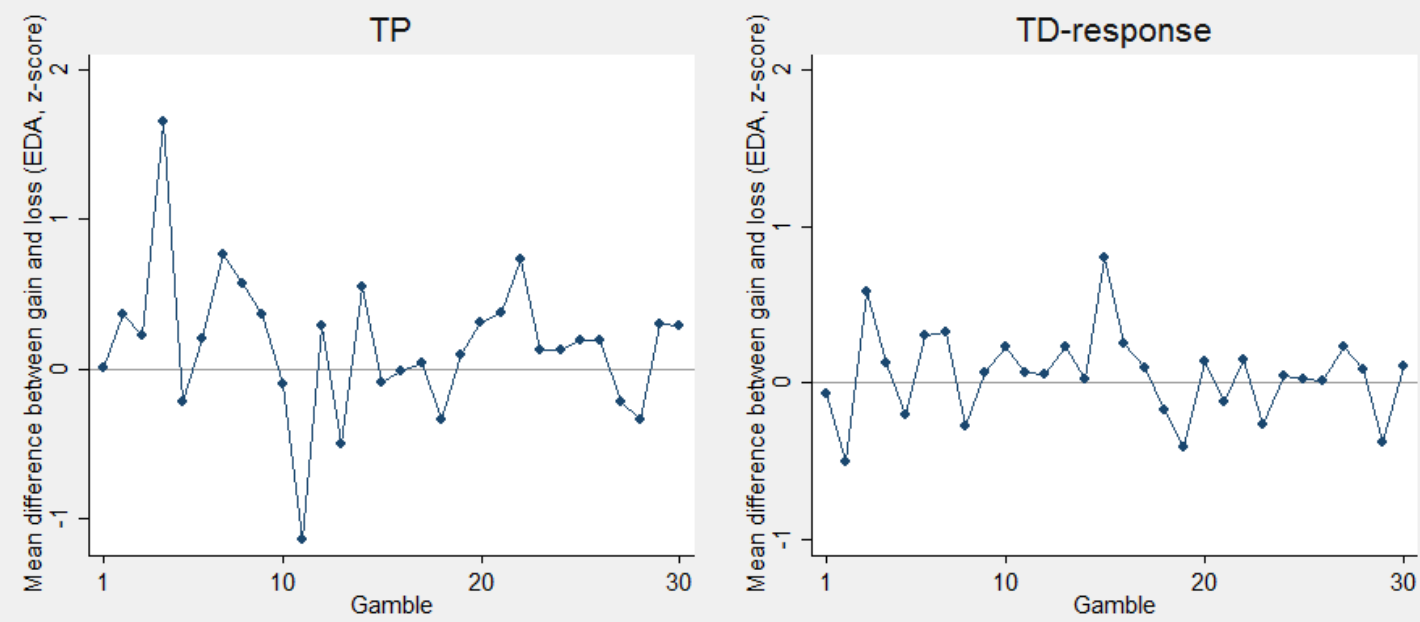

Note: The gambles are ranked by EVR, from lowest to highest. 
Figure A1. Predicted probability to gamble, by EDA, treatment and domain
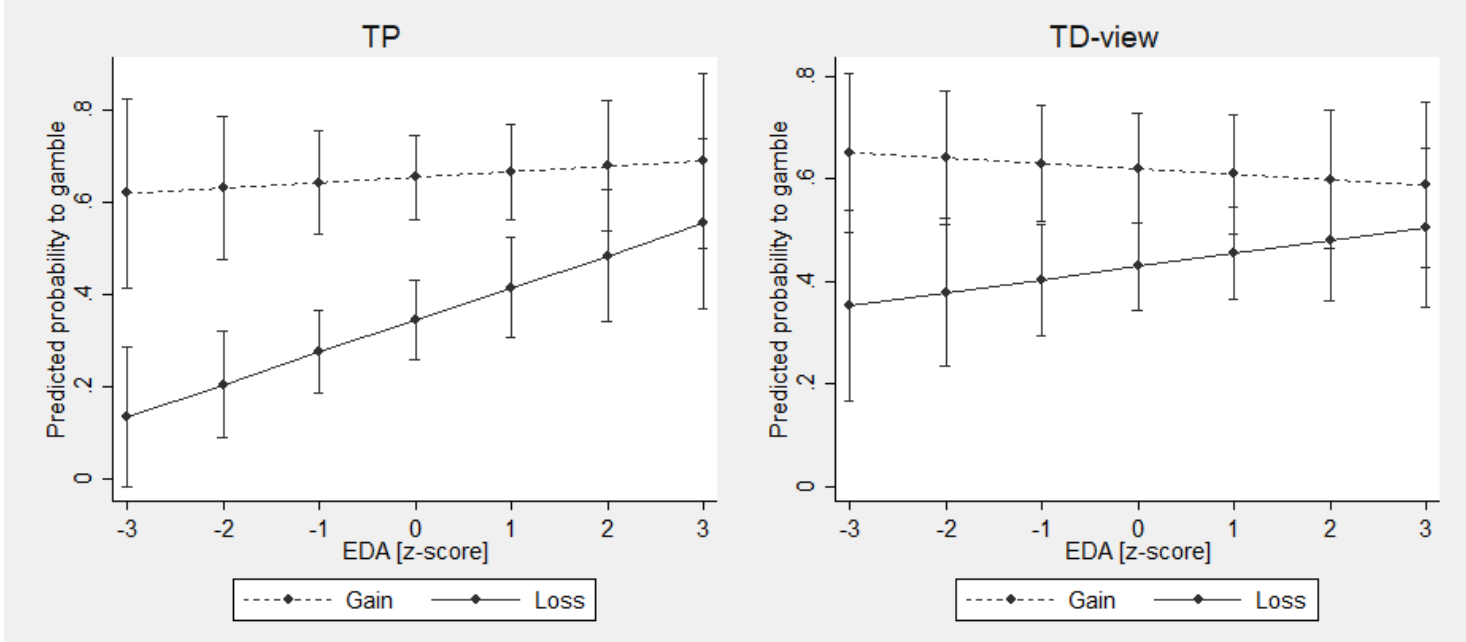

Note: Linear prediction calculated from OLS regressions of subjects' binary choice (=1 if chose to gamble) on EDA, standard errors clustered at the level of the individual. Bars represent $95 \%$ confidence intervals. 
Figure A2. Gain-loss difference (average EDA) across all gambles in the experiment
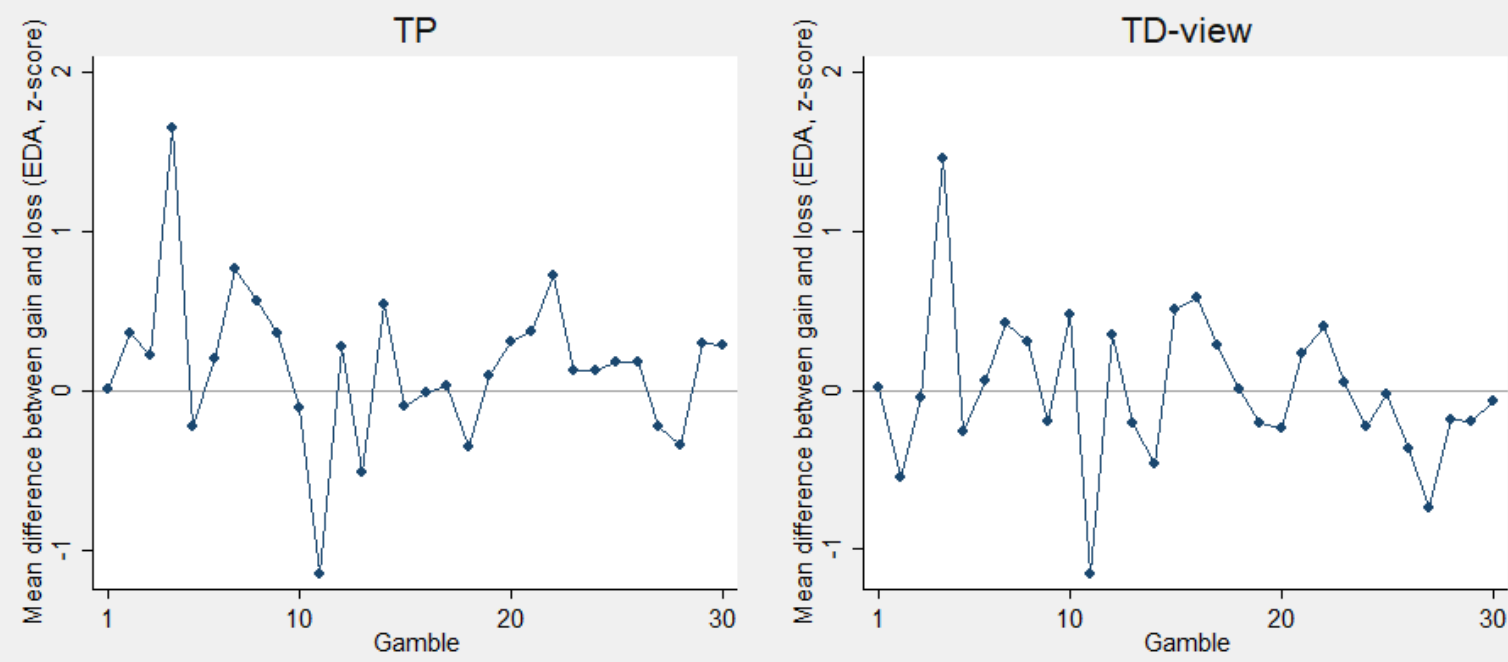

Note: The gambles are ranked by EVR, from lowest to highest. 